\title{
Article
}

\section{Oral health and the Millennium and Sustainable Development Goals}

\author{
Crean, Stjohn and Batchelor, Paul
}

Available at http://clok.uclan.ac.uk/28154/

Crean, Stjohn ORCID: 0000-0001-9336-8549 and Batchelor, Paul (2019) Oral health and the Millennium and Sustainable Development Goals. Faculty Dental Journal, 10 (2). pp. 58-60. ISSN 2042-6852

It is advisable to refer to the publisher's version if you intend to cite from the work. http://dx.doi.org/10.1308/rcsfdj.2019.58

For more information about UCLan's research in this area go to http://www.uclan.ac.uk/researchgroups/ and search for < name of research Group>.

For information about Research generally at UCLan please go to http://www.uclan.ac.uk/research/

All outputs in CLoK are protected by Intellectual Property Rights law, including Copyright law. Copyright, IPR and Moral Rights for the works on this site are retained by the individual authors and/or other copyright owners. Terms and conditions for use of this material are defined in the policies page.

\section{CLoK}

Central Lancashire online Knowledge www.clok.uclan.ac.uk

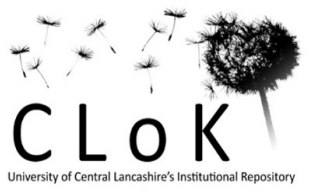


Oral Health and the Millennium and Sustainable Development Goals.

\section{StJohn Crean \\ Paul Batchelor}

\section{Introduction}

The world is a complex and at times a mystifying place. Sense and reason struggle for visibility amongst national terms of reference constructed around individual nation's needs, pride and in some cases survival. Embedded amongst these "instincts" lurk the more menacing forces of power, influence and control. It is from such hybrid climates that the globally facing Millennium Development Goals (MDGs) and succeeding Sustainable Development Goals (SDGs) emerged.

Both MDGs and SDGs demand global changes aiming to improve the human experience. The vanguard MDG's have ignited a legion of opinions about their influence and impact. The SDGs, attempt to broaden and provide granularity around national, international and global frameworks to ensure planetary benefit.

\section{Millennium Development goals.}

The MDGs comprised of 8 goals, 21 targets and 60 associated indicators, drawn up by a group of UN technical experts in 2000 . They aimed to "change the world" but more specifically to target and then eradicate extreme poverty (earning less than $\$ 1.25$ a day), by 2015 . They were agreed by world leaders assembled after 189 countries signed the "Millennium Declaration" (2). The MDGs aimed to; eradicate extreme poverty and hunger, achieve universal education, promote women power and gender equality, reduce child mortality, improve maternal health, fight malaria, HIV/Aids and other diseases, design for environmental sustainability whilst demanding global development partnerships (1).

There were a number of quantitative targets within the goals to be reached by 2015 . These included; halving those who suffer extreme poverty, reduce by two thirds the child (under five) mortality and reduce by three quarters the maternal mortality. The 
remaining goals and targets were qualitatively set using the term "halted" most frequently (3).

\section{Sustainable Development goals}

In contrast to the MDGs the succeeding SDGs, running from 2015 to 2030 , comprise of 17 goals with 169 individual targets. The goals are wider ranging, less generalised and incorporate the following; ending poverty in all forms, ending hunger with improved food security and sustainable agriculture, ensure healthy lives and health for all, ensure inclusive and equitable education to achieve gender equality and empower all women and girls, ensuring water and sanitation, ensure access to sustainable and affordable energy, guaranteeing employment with decent jobs, promoting economic growth, providing infrastructure to promote industrialisation and innovation, reduce inequality within and between countries, create safe and sustainable cities, influence consumption and production behaviours, combat climate change urgently, protect and conserve oceans and marine resources, combat processes which threaten ecosystems, promote peace justice for all and accountable communities but most of all promote committed global partnerships (1).

The UN Statistical Commission has assembled an Inter-Agency and Expert Group, to embrace the widest most effective data collection methods, to monitor SDG progress. However, the UN also expects each nation to develop its own impact assessment methods, to promote national ownership (4).

\section{Lessons learned to ensure global health going forward}

Both the MDGs and the subsequent SDGs have drawn opinions from across a wide spectrum of health and political arenas. The SDGs has raised issues which are we believe, a sanguine reminder of the challenges that lie ahead toward achieving the global health aspirations in the next 15 years. Lessons that need to be taken on board appear to us to be clear. 
Without favourable environmental conditions human beings will never be able to create and enjoy the conditions associated with global health. Two elements lie at the heart of the associated issues. Firstly, climate change commitments become the key target for the UN to achieve. The lack of uniformity and agreement in this arena is of concern and it is time for the current interim moratorium to bring the major players back to the table to agree the way forward. The Paris agreement legislative position is something those charged with delivering the SDGs can only look enviously upon. Without a healthy planet what hope of healthy people?

Secondly, issues raised time and time again around human rights and equality, if not confronted, will obstruct all hopes of a uniform global outcome. Whilst the goals will and have revealed some successful examples of implementation, if the approaches are not available to all citizens what hope of progress? Allied to this is the aspiration to target complete eradication of issues such as poverty and hunger. Noble in their wording but likely unrealistic in achievability. Their effect, already emerging is to distract some players, whereby they lose interest and side-line the overall aspirations.

We believe that the invitation to private investment is risky as it allows a cherry picking approach to companies determined to provide a return to shareholders. Thus investors should be invited to focus on the less capable countries and receive tax benefits inversely proportional to the starting performance level of the region.

The ability of countries, who are starting from a lower level than others, hampered by unequal capacity and insufficient funds available to support the goals, means we feel the targets need to be applied, not uniformly across the planet, but focused on the "low hanging fruit". The lesson from the MDGs is to allow countries to focus on a prioritised list of goals, constructed on the likelihood of achievability. The UN should oversee the wider picture of agreed targets to ensure that the richer countries are not allowed to focus on areas which will not stretch them and that the overall targets initially agreed and approved, will collectively work toward the SDGs overall goals. Poorer countries should be rewarded for trying, judged on progress rates and performance weighted against richer countries who are expected to reach their stated target (10). One simple lesson to be learned from the MDGs is the need to change the assessment process. It has been suggested to turn to calculating rates of progression rather than absolute numbers. If this approach had been adopted when assessing the MDGs, it has been 
estimated that areas such as Sub-Saharan Africa, would have been reported as successful rather than as having failed on account of not achieving a specific number (5). This approach assumes a linear progression model but even applying a sigmoidal theory, disadvantaged countries continue to show advances. This I believe will be key to engage and keep engaged all those signatory countries (6).

\section{The implications for oral health}

While oral health was not mentioned directly in either the MDGs or SDGs documents, numerous authors have highlighted how poor oral health impacts on the well-being of individuals. For those working in the oral health sector this may seem a disappointment, not least as there are few health conditions which have such a wealth of data on the conditions which they try and address, indeed to many, this simply reinforces the view that oral health care services are regarded as a 'Cinderella' service. This is too simplistic an argument and adopts an approach that continually fails; if one shouts louder then people will hear you. Despite the continual voice highlighting the need to 'remember' oral health when planning care arrangements, investment and development remains limited. Why and how might they be addressed? The issues described above arise for three key reasons. First, the recognition of the limitations of clinical disease measures alone as an indicator of oral health. The data that are routinely collected such as DMF or CPITN scores while providing an indication of equity and perhaps more importantly, how services may have contributed to changes in overall levels, have limited value in assessing any variation in such scores on the overall health impact: the same DMF score at 6 and 60 years of age has very differing implications. While they have value to the dental professions, for those outside the sector their meaning and hence value is covered in clouds of vagueness.

Those arguing for dental resources and looking where services can contribute to the MDGS and SDGs goals need not to shout louder but to to change the language used. It is the impact of the disease and its implications which are important. How does a DMF of 2 at 12 years of age impact on the development of a child's education. Does 
a change of 0.5 in a DMF within a population matter? As Benzian et al. highlighted, there is no systematic research or concepts to link oral health and the MDGs (7). The authors went on to suggest a differing framework for where oral care services can make such a contribution based on what they termed direct and indirect impacts. For the former, examples included difficulty in eating or swallowing and malnutrition; for the latter, absence from school education or work.

Addressing both of these through improving levels of oral health would contribute to the broad goals of SDGs. The key point is in ensuring the right data are collected. Such an approach would allow the impact of oral health to be compared to those arising from other health problems and would help make the case, or not, for investment. Furthermore, such an approach would also allow comparison for differing interventions. All care systems suffer from resource constraints and a mechanism for prioritising interventions to meet the goals of the system, whether based on the MDGs, SDGs or others, is required. Using an impact based index arrangement in line with the goals of the MDGS and SDGs goals would allow a conversation to take place with all care providers but based on common goals, for example improving school attendance or improving mothers' well-being. Such an approach takes forward the work by Listl et al. who while highlighting the cost of dental care, did not address the wider question of which strategies would provide better solutions (8).

Second, and linked to the above, is the recognition of the importance of the commonality in the antecedents or social determinants of general and oral health. For the vast majority of health conditions, those living in the worse socio-economic conditions will tend to have poorer levels of oral health but they will also have poorer levels of general health. Individuals with a diet high in sugar will develop not only dental caries but also diabetes and tend towards obesity. While caries levels may be used as a marker for future health problems, the key lies to addressing sugars consumption, not simply changing the caries experience. After all fluoride exposure does alter the rate at which caries occurs but does little if anything about the likelihood of diabetes or obesity.

At a societal level, as highlighted previously, it is the environment that individuals find themselves in that is a key factor which needs to be addressed: there is little benefit in providing excellence in standards of treatment only to place the individual back into 
the very environment that contributed to the problem initially without changing it. This raises threetwo important aspects when considering how best the dental professions can contribute to the SDGs. Firstly, - Tthere is a need to ensure consistencythe commonality in the health messages given and secondly a unified focus for the subsequentthe need for-collaborative actions. - Tthe term often used is "integration of care", to address the challenges that ill health produces in an efficient and effective care arrangement. To achieve these two aims demands a and requires the third challenge, namely that of addressing educational and training of care workers, met.

Currently the training of the oral health care workforce tends to occur in isolation. There is a lack of "cross craft" education which helps create the isolationism and creates the problems described above. There is a need for all of the care workforce to understand and appreciate the challenges that the Society that they work in pose. This is not to argue for wholesale change, simply to help ensure that there is an appreciation of the commonality in cause and understanding of each others' roles. One suggested approach is that by Pálsdóttir et al. who argued for:

"the closer alignment of education curricula to community needs, targeted student selection with priority given to underrepresented populations, interprofessional training in underserved locations and in areas of need, expansion of faculty in rural areas, and elose partnership with communities."

Curriculum to be aligned with health needs such that health and social needs within communities guide education, research and service programmes and graduates are thus better prepared to address them. (9).

\section{Final thoughts}

The MDGs and SDGs were designed to hopefully provide conditions for future generations toward a healthy future. Clearly, global politics, abilities and long-term outlooks need to be aligned. What is clear however, is that without a firm or even a legal accountable commitment to upstream issues such planetary health, downstream human health targets may elude all but the most advantaged. There is much work to be done.
Commented [TN1]: This sentence is too long (very confusing) and I don't think it is grammatically correct. Please rewrite.

Commented [TN2]: I can't find this quote in ref 9. Please advise. 
If oral health care professions are to maximise the potential that they can make to the MDGs and SDGs goals, the above challenges need to be addressed as a start. It requires those leading the professions to see the value in working together on behalf of the populations they serve.

\section{References}

1. https://www.fivetalents.org.uk/un-sustainable-development-goals/

2. Louis Emmerij, and Thomas G. Weiss, UN Ideas That Changed the World. R Jolly - 2009 - Bloomington: Indiana University

3. Report of the Ad Hoc Committee of the Whole of the Twenty-First Special Session of the General Assembly, Key Actions for the Further Implementation of United Nations General Assembly - 1999 - UN New York.

4. IAEG-SDGs. Inter-agency Expert Group on SDG Indicators https://unstats.un.org/sdgs/iaeg-sdgs/

5. Fukuda-Parr S, Greenstein J, Stewart D. How Should MDG Success and Failure be Judged: Faster Progress or Achieving the Targets? World Development, Volume 41, January 2013, Pages 19-30

6. Hailu, Degol; Tsukada, Raquel (2011) : Achieving the Millennium Development Goals: A measure of progress, Working Paper, International Policy Centre for Inclusive Growth, No. 78, International Policy Centre for Inclusive Growth (IPCIG), Brasilia

7. Benzian $\mathrm{H}$, Hobdell M, Holmgren $\mathrm{C}$, et al. Oral Health and the Millennium Development Goals Conference presentation at 138st APHA Annual Meeting and Exposition 2010 (Available https://www.researchgate.net/publication/266901331 Oral Health and the Millennium Development Goals).

8. Listl S, Galloway J, Mossey PA, et al. Global economic impact of dental diseases. J Dent Res 2015; 94: 1355-61. 
9. Pálsdóttir B, Björg Pálsdóttir, Jean Barry et al. -Training for impact: the socioeconomic impact of a fit for purpose health workforce on communities. Human Resources for Health 201614:496obb N, Fisher J, et al. Enabling universal soverage and empowering communities through socially accountable health workforce education. Health employment and economic growth: an evidence base. In: Buchan J, Dhillon IS, Gampbell J, (Eds). Health Employment and Economic Growth: An Evidence Base. Geneva: World Health Organization; 2017.

10. Easterly, W. (2009). How the millennium development goals are unfair to Africa. World Development, 37(1), 26-35.

Professor StJohn Crean

BDS MBBS FDSRCS FFGDP(UK) FDSRCPS (Glas) FRCS FRCS(OMFS) PhD PGCertMed Ed (Camb) FHEA

Pro Vice Chancellor ( Clinical and Health)

Professor of Medicine in Dentistry

Consultant Oral and Maxillofacial Surgeon

Allen Building, Room AL005

University of Central Lancashire

Preston PR1 2HE

+44(0)1772893393

$\square$ screan@uclan.ac.uk

\section{Paul Batchelor}

Honorary Clinical Professor, School of Medicine, University of Central Lancashire, Preston PR1 2HE Batchelor, Paul<p.batchelor@ucl.ac.uk>
Formatted: Font: (Default) Arial, $12 \mathrm{pt}$

Formatted: Font: (Default) Arial, 12 pt 